\title{
THE NON-MAINTENANCE COST - INSTRUMENT OF EFFICIENT MANAGEMENT WITHIN INDUSTRIAL ENTERPRISE
}

\author{
CUCUIOAN, Associated Professor, cucuioan2002@yahoo.fr \\ University of Petroşani, \\ CODRUT,A DURA, Associated Professor, codrutadura@yahoo.com \\ University of Petroşani,
}

\begin{abstract}
The analysis and the assessment of maintenance costs for technological equipment play a dominant role among maintenance management issues in industrial enterprises. An original approach to this problem is based on the non-maintenance costs which can be defined through the expenses caused by the non-maintenance of the functional characteristics of industrial technological equipment. Practically, the equipment inefficiency (non-maintenance) costs can be assessed by the difference between provisioned operation cost to be obtained in an ideal situation (according to which the equipment dose not undergo any breakdown) and the real situation of the results obtained in the same period. The assessment model for non- maintenance costs proposed in the paper involves the covering of the following stages: diagnosis, the definition of ideal situation, the evaluation of the results' accounts and the calculation of the non-maintenance cost as such.
\end{abstract}

Maintenance costs can be analyzed according to their nature, their destination and their type of intervention; these costs can be imputed to the operating method (of equipment, tools, technological mechanisms) and to the investment program.

The analysis and the evaluation of the maintenance costs of functioning technological equipment play an important part in the management of the maintenance activity and in the general management of industrial companies. This evaluation illustrates the importance of the maintenance function by sensitizing all of the company's internal and external factors in order to be able to encourage an efficient policy in this field.

The new method of analyzing maintenance costs consists in evaluating non-maintenance costs (or inefficiency/non-efficiency costs) which implies the adaptation of basic accountancy systems of maintenance activities through a close control of the industrial company's costs.

The term "inefficiency cost" (non-maintenance) was proposed in the 80 s by a group of people from the National Bureau of Maintenance from France led by Professor F. Bouchy; the tern was assimilated with the "non-quality" concept which had already been implemented in the production systems of the industrial units from developed countries.

The flowing version has been accepted as a general definition of the non-maintenance cost: "the costs resulted from non-maintaining the functional characteristics of the industrial technologic equipment."

The idea of the inefficiency cost is not new among people in charge with maintaining or upkeeping of a state/condition, thus it is mentioned that: "the old Chinese, heirs of Confucius's wisdom, used to pay the doctors (healers) a monthly fee as long as they were healthy and they stopped paying it when they were ill. This method ensured the incomes of healers by making them keep their clients healthy and offer medical assistance as soon as they got sick". 
Analogically, the maintenance (up-keeping) of the technological equipment from a factory can be treated as "curative" medicine, because it means that the maintenance activity is not paid for whenever there are repair-works to be done and it is rewarded/remunerated when everything works well. Such an approach could have been possible during the $50 \mathrm{~s}$, as a consequence of introducing a preventive maintenance policy for the functions of technologic equipment but it would not have lasted due to the rapid progress of production technologies and specific equipment.

At the beginning of the $80 \mathrm{~s}$, the concepts and the approach of maintenance policies within industrial companies were radically changed; thus in the process of managing maintenance activities new evaluation methods were introduced, among which "measuring the maintenance and inefficiency costs" plays the most important part in estimating the results within this sector of activity.

The practical method for determining inefficiency costs results from the definition formulated by Professor C. Riveline regarding decision cost, according to which the inefficiency cost for certain equipment represents "the difference between the levels of effective expenditures resulting from the process of making the decision of carrying out the maintenance activity or not." This decision means choosing between a real situation, a situation that resulted from operating the equipment or tools during the production process and a production achieved according to the real situation of their functioning, as compared to an ideal situation or to a situation of reference regarding equipment functioning and its production. In this respect, knowing the inefficiency (non-maintenance) cost represents a way of optimizing the general management and the maintenance within that company.

As mentioned above, the inefficiency (non-maintenance) cost of equipment will be determined by the difference between operating results which were estimated to be obtained in an ideal situation, a situation of reference and according to which the equipment has no deficiencies/flaws/malfunctions all along the analyzed period; and the present situation, the real situation respectively regarding the results obtained during the same period. This analysis can be illustrated graphically as well, just like in figure 1. 
COSTS

INCOME

PROFIT

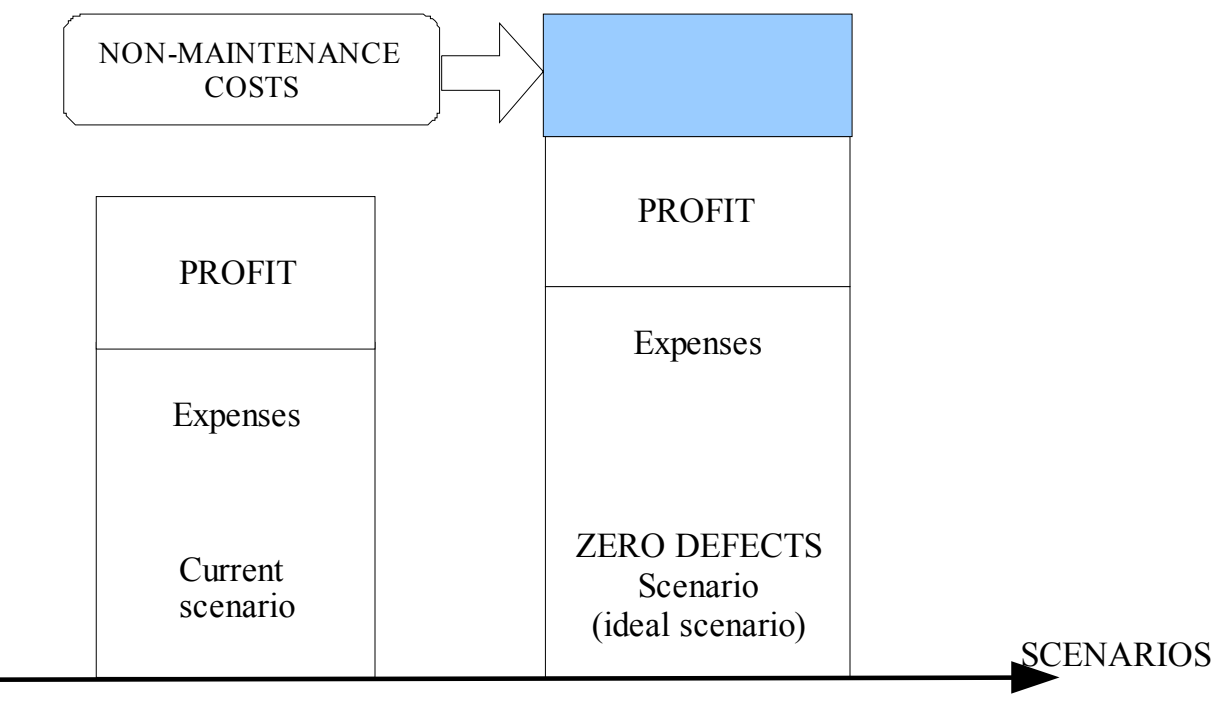

Figure no. 1: Scenario comparation

For the economic analysis of the final economic results, of the net profit respectively, profit which can be obtained as a consequence of an optimum functioning of technologic equipment and installations within a production unit, it is necessary to highlight/mark out the main expenditure and income accounts with their closing balance based on which we can establish the efficiency level of the analyzed unit. Thus, table 1 illustrates the analysis of the closing balances of the accounts and the method of calculating the results, the profit which was made by the productive activities within the industrial company.

Thus table 1 represents a model of the sales analysis for the analysis account and for the way the results are calculated, respectively of the profit obtained as a result of the productive activity in the industrial firm that we analyze.

Table no.1: Analysis model of the efficiency of a production unit

\begin{tabular}{|l|l|l|l|}
\hline \multicolumn{2}{|c|}{} & $\begin{array}{l}\text { Balance at the } \\
\text { end of the } \\
\text { period }\end{array}$ & $\begin{array}{l}\text { Balance at the } \\
\text { end of the period }\end{array}$ \\
\hline Operational expenses : & & Operational income : & \\
\hline $\begin{array}{l}\text { - Spare parts, products an, } \\
\text { raw materials acquisition. }\end{array}$ & $\mathrm{x}$ & - Direct sales of goods & $\mathbf{X}$ \\
\hline
\end{tabular}




\begin{tabular}{|c|c|c|c|}
\hline - Variation of stocks & $\mathbf{X}$ & - Sold production & $\mathbf{X}$ \\
\hline - Taxes & $\mathbf{X}$ & - Production stock & \\
\hline - Social insurances costs & $\mathbf{X}$ & - Immobilized output? & $\mathbf{X}$ \\
\hline \multirow{2}{*}{$\begin{array}{ll}- & \text { equipment deprecation } \\
\text { costs }\end{array}$} & $\mathbf{X}$ & - Operational subsidy & \\
\hline & & - Provisions & $\mathbf{X}$ \\
\hline Total & $T_{1}$ & Total & $T_{2}$ \\
\hline Operational result & \multicolumn{3}{|c|}{$T_{2}-T_{1}$} \\
\hline Financial costs & $\mathbf{X}$ & Financial income & $\mathbf{X}$ \\
\hline Extraordinary costs & $\mathbf{X}$ & Extraordinary income & $\mathbf{X}$ \\
\hline $\begin{array}{l}\text { Employee participation to } \\
\text { operational results }\end{array}$ & $\mathbf{X}$ & & \\
\hline Profit tax & $\mathbf{X}$ & & \\
\hline Total & $T_{3}$ & Total & $T_{4}$ \\
\hline
\end{tabular}

From Table 1 results that the proposed analysis emphasis the operation results of the equipment and technological installation in «the operational results account $\Rightarrow>T_{2}-T_{1}$ ». This results are directly correlated with the availability of the equipment and this indicator contributes to the growing of the operational results and the final clear results, respectively to the growing of the net profit obtained as the result of the exploitation when the equipments in the analyzed company are efficiently used. $\ll$ Net resultes $=\mathrm{T}_{4}-\mathrm{T}_{3} »$.

\section{Evaluation model of the non - efficiency cost of a production unit}

Applying the model consists in going trough three levels:

- establishing diagnostic;

- defining the ideal / reference scenario;

- estimation of the results account and calculation of the non - maintenance cost.

I. Determining the diagnosis

Consists in the assessment of relative indicators regarding precedent losses, especially those regarding:

- severe defects;

- stops caused by malfunction of some technological equipment;

- bad quality of goods caused by equipment malfunctions (such as rejects, rectifications, etc

) 
Theoretically this stage involves a multidisciplinary and multi-sectorial relation inside the product unit for a good evaluation of costs showed (in a constant currency). For its achievement it is necessary to identify the methods, processes and working techniques and to establish inside multidisciplinary analysis groups the values taken into account. Even though some information is already to be found in general or analytical book-keeping, it is necessary that the proposed situations be analyzed and re-evaluated from the costs point of view.

The diagnosticaly stage supose besides identification and registering the damage kind, estabilishing the consequences over the equipements such as the losses registraded because those events. So in schedule no 2 is prposed an analysi exemple over this elements in the diagnosticaly stage.

The diagnostics phase should also consist (along with the identification and recording of the defect type) in assessing the consequences the defects have on equipments as well as the incurred losses. Thus table 2 proposes an analysis example regarding these elements of the diagnostic phase.

Table no. 2: The diagnoze of efficiency pattern of the maintenance activity

\begin{tabular}{|c|c|c|}
\hline DEFICIENCES & CONSEQUENCES & RESULTS / LOSSES \\
\hline $\begin{array}{l}\text { - serious defect on } \\
\boldsymbol{E}_{\boldsymbol{l}} \text { equipment... }\end{array}$ & $\begin{array}{l}\text { - unavailability for } \\
\text { "m" [days] }\end{array}$ & $\begin{array}{l}\text { - penalties; } \\
\text { - output losses; } \\
\text { - overtime payment for the } \\
\text { restoring of the Ei equipment. }\end{array}$ \\
\hline $\begin{array}{l}-\quad \text { production stop caused } \\
\text { by malfunction of the } \\
\boldsymbol{E}_{2} \text { equipment... }\end{array}$ & $\begin{array}{l}\text { - unavailability for } \\
\text { "t" [hours] }\end{array}$ & $\begin{array}{l}\text { - the recovery costs for } \\
\text { the lost production; - - - } \\
\text { restoring in function costs }\end{array}$ \\
\hline $\begin{array}{l}\text { - minor defect of the } \\
\text { machine } \boldsymbol{E}_{3 . .}\end{array}$ & $\begin{array}{l}\text { - growing rate of } \\
\text { unavailability }\end{array}$ & - efficiency losses.... \\
\hline $\begin{array}{l}\text { - low quality products } \\
\text { caused by the inadequate } \\
\text { functioning of technological } \\
\text { equipment }\end{array}$ & $\begin{array}{l}\text { - rejets rate increasing; } \\
\text { - redevelopment of some } \\
\text { products. }\end{array}$ & $\begin{array}{l}\text { - efficiency losses ; } \\
\text { - reconditioning and recovering } \\
\text { costs; } \\
\text { - product testing costs. }\end{array}$ \\
\hline
\end{tabular}

At the end of this stage costs will be classified acording to their influence in the total non - meintenance cost. For this aspet, two categories are suggested:

A. - costs that involve an increase of operational costs during the analyzed period, named

[C], witch include:

- insurance costs;

- uncovered losses;

- safety middle stocks;

- corection for the products; 
B. - costs due to the decrease of the income, named [D] which include mainly:

- the reduction of the profit margin;

- penalities stipulated by contract for not meeting the stipulated delivery times;

- income losses caused by lesser-quality products sold under regular price, etc.

At the same time, finalizing the diagnosis stage implies the analysis of the following aspects:

- paleative measures that were taken for reducing the consequences caused by the defects of some technological equipments;

- weight of the identified costs caused by the defect event, in the global value of the evaluated costs;

- inefficiency costs that can be identified directly or estimated according to book-keeping data.

\section{Defining the ideal scenario}

The second stage consist in designing and developing of a scenario in which equipments suffer no defects. This estimation should represent a realistic situation, respectively a situation that can have stability for the entire analyzed period.

The scenario must be an ideal one, that is to say it should present an ideal situation in which the production unit is able to optimize/improve the production activity in this direction. The scenario can be imagined based on the existing means/capital goods within the unit at the time of the analysis and based on the demand of products, either using the entire productive potential (the maximum production capacity) for the estimation of the ideal situation or using only the effective capacity, the capacity of equipment to turn out a certain level of production, which implies reducing the total capacity by the value of the capacity of extra or unused equipment. Therewith, the evaluation of maintenance costs must be done based on the actual costs (costs which were identified the moment he analysis was begun) and on the production estimated to be turned out during the analyzed period.

Remark 1: In defining the reference situation, some fictional evaluation aspects must be set aside and only realistic and possible hypothesis should be retained; the production unit has to make efforts to reach the parameters estimated at the level of "the situation of reference" in order to improve the existing situation and having in view one of the following hypothesis:

$>\mathbf{I}_{1}$ - the increase of production will be possible by eliminating losses (making up for the unavailable period), on condition that extra production, through the elimination of the unavailable period of the technologic equipment is sold at the same price as the target production and by the time the analysis is being carried out.

$>\mathbf{I}_{2}$ - the increase of production will be possible according to hypothesis $\mathrm{I}_{1}$ but on condition that the selling price of the extra production is reduced.

$>\mathbf{I}_{3}$ - the production remains unchanged for commercial reasons; under the circumstances it is possible to supervise the efficient use of equipment and personnel by reducing them to an economic optimum state.

Choosing the commercial hypothesis according to those mentioned above is of strategic importance for the future of the production unit in case the diagnostic analysis reveals a reduced usage capacity of the productivity in that unit. 
Remark 2: The hypothesis for the ideal situation on which the company is going to focus can require great commercial efforts in order to increase sales on market segments; this means that the effects will be felt progressively over a certain period of time.

\section{Calculating the inefficiency (non-maintenance) cost}

The method of calculating the inefficiency cost of the maintenance activity consists of a number of 6 (six) phases. To better understand the method, we used graphic representations from which you can deduce the differences between the analyzed indicators, between the ideal situation (reference situation) and the real one.

The method includes the analysis regarding the result account obtained by the unit before taxation, the operating result account respectively; because of this we will calculate the income and expenditure for each category from table 1; this represents the approach of the analysis from the point of view of expenditures made by the company and not by the departments in charge.

Just like we mentioned above, the actual calculus of the non-maintenance cost has the following phases:

- Phase I which consists in correcting the base of expenses and income of the real situation with the values $[\mathrm{C}]$ and $[\mathrm{D}]$, mentioned in stage 1. According to this correction, the expenditures $(\mathrm{CH})$ and the income $(\mathrm{V})$ will have the following values (as shown in figure 2):

$$
\mathrm{CHc}=\mathrm{CH}-\mathrm{C} \quad \text { and } \quad \mathrm{V}^{\prime}=\mathrm{V}+\mathrm{D}
$$

- Phase II calculates the increasing coefficient of production which is noted $\mathrm{K}$ and can be determined based on the global capacity of the production unit, $K=1 / \mathrm{R}$ respectively. This can also be determined based on the commercial hypotheses illustrated in stage 2 . Thus, in the case of the first hypothesis $\mathrm{I}_{1}$, we encounter the following situation:

The increasing coefficient $\mathrm{K}$ will be determined only after the production characteristics of the unit have been established. Thereby, in case the maximum production is sold at a medium price and the real situation is characterized by the indicators presented below:

- $\quad$ the global unavailability rate (i);

- $\quad$ the rejection rate of the final production $(\mathrm{r})$;

The production will be calculated as a multiple of $K_{P}$, the value of which is given by the relation:

$$
\mathrm{K}_{\mathrm{P}}=1 /(1-\mathrm{i})
$$

while in the case of incomes it is multiplied by $\mathrm{Kv}$ which is determined by the equation:

$$
\mathrm{Kv}=\mathrm{l} /(1-\mathrm{i}-\mathrm{r})
$$

- Phase III estimates the incomes corresponding to the ideal situation "zero malfunctions/deficiencies/flaws", noted $\mathrm{V}_{\mathrm{z}}$ :

$$
\mathrm{Vz}=\mathrm{KvxV}=(\mathrm{V}+\mathrm{D}) /(1-\mathrm{I}-\mathrm{r})
$$

- Phase IV estimates the expenditures corresponding to the ideal situation "zero malfunctions/deficiencies/flaws". 
The operating costs of the unit will not increase according to $\mathrm{K}_{\mathrm{P}}$ coefficient (the production increase coefficient, determined in phase II) because some categories of expenses remain constant in relation to the increase of production, while others are in direct proportion with the increase of production or in partial proportional relation.

For example the expenditures with materials, raw materials, services, etc will be in direct proportion with the increase of production. As far as the expenses with the personnel are concerned we can state that the number of operators (working personnel) stays unchanged, but the increase of production could lead to the increase of the number of maintenance personnel. At the same time, the increase of sales could lead to an increase of the number of people working in the sales department; these increases reveal that this category of expenses is in a partial ratio with the production growth.

As a consequence of those mentioned above, for the increase of a unit's productivity, of an evolution toward an ideal situation respectively, we estimate an increase of expenses calculated during phase I with the help of $\mathrm{K}_{\mathrm{P}}$ value for some of them which correspond to $(\mathrm{CHc})$ in a rate of $\mathrm{P}$ $(\mathrm{P}<100 \%)$, while the other expenditures $(100 \%-\mathrm{P})$ remain constant. Thus, the level of operating costs for the "zero malfunctions/deficiencies/flaws" reference situation can be determined by the following equation:

$\mathrm{CHz}=\mathrm{CHc}[\mathrm{Kp} \times \mathrm{P} \%+(100-\mathrm{P} \%)]=(\mathrm{CH}-\mathrm{C})[\mathrm{Kp} \times \mathrm{P} \%+(100-\mathrm{P} \%)]$

- $\quad$ Phase $V$ determines the operating result of the production unit in the case of "zero malfunctions/deficiencies/flaws" reference situation:

$$
\mathrm{Rz}=\mathrm{Vz}-\mathrm{Chz}
$$

while the global inefficiency (non-maintenance) cost could be calculated according to the following relation:

$$
\mathrm{CNM}=(\mathrm{Vz}-\mathrm{V})-(\mathrm{CHz}-\mathrm{CH})
$$

The result of the reference situation and the level of non-maintenance cost are illustrated in figure 2 . 


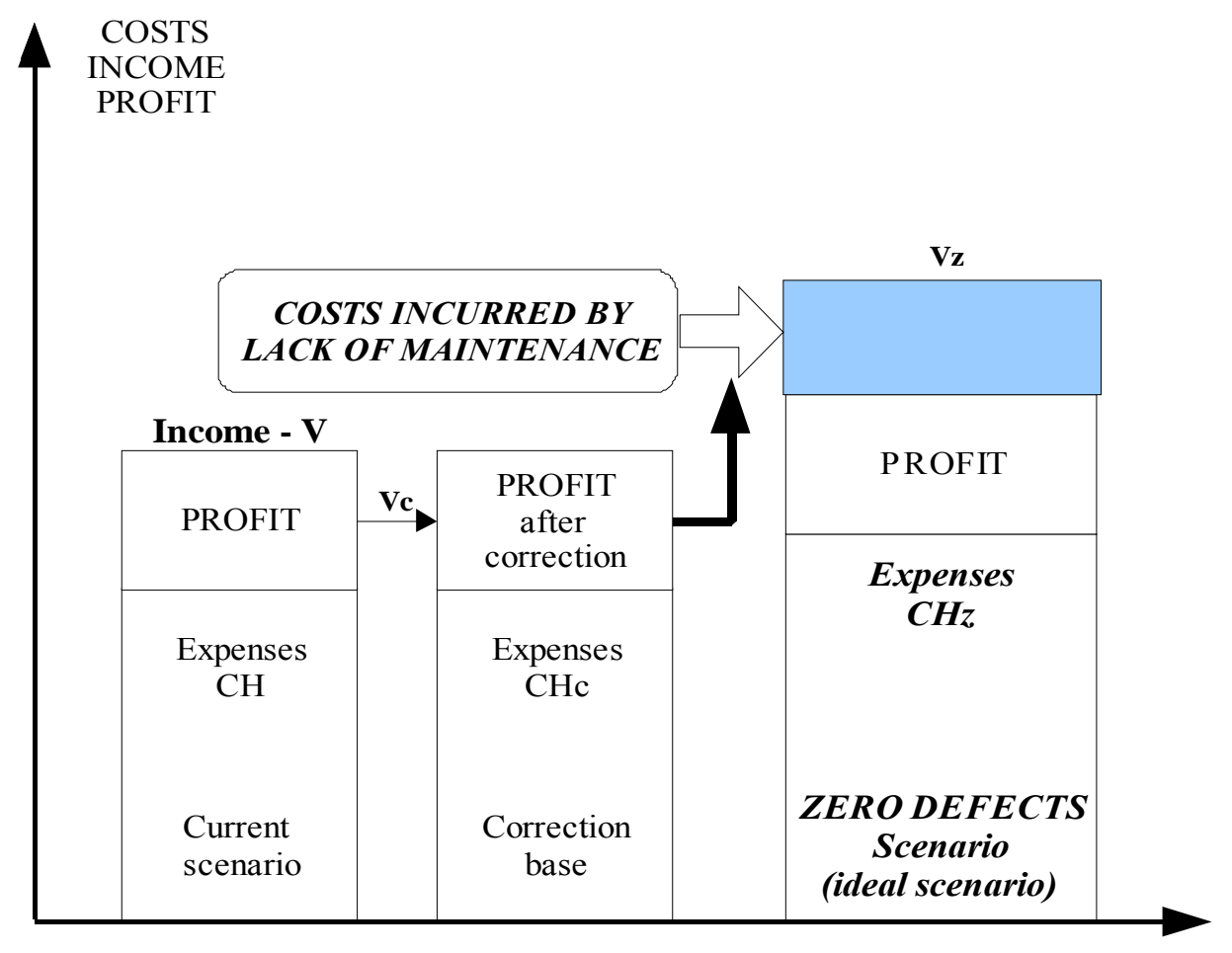

Figure no.2: Graphical representation of profit decrease and non-maintenance costs

Considering the calculations presented in phases $1-4$, we can write the following relation for the non-maintenance cost:

$$
\mathrm{CNM}=[\mathrm{Kv}(\mathrm{V}+\mathrm{D})-\mathrm{V}]-\{(\mathrm{CH}-\mathrm{C})[\mathrm{Kp} \times \mathrm{P} \%+(100-\mathrm{P} \%)]-\mathrm{CH}\}
$$

where: $-[\mathrm{Kv}(\mathrm{V}+\mathrm{D})-\mathrm{V}]$ represents the level of reducing the incomes between the two situations; - $\{(\mathrm{CH}-\mathrm{C})[\mathrm{Kp} \times \mathrm{P} \%+(100-\mathrm{P} \%)]-\mathrm{CH}\}$ means increasing the costs for the ideal situation in comparison with their real level

- Phase VI which consists in analyzing the non-maintenance cost and in identifying the elements that led to the reduction of the global productivity, mainly because of maintenance activities. This analysis intends to establish the causes which led to the existence of "nonmaintenance costs" (NMC); then, the value resulted from the calculation of this cost will be attributed to the main technologic equipment in order to determine the rate of influence of each machine on the level of non-maintenance costs.

\section{Conclusions}

The switch from regular maintenance to maintenance according to non-maintenance costs implies altering the related objectives for the industrial unit, from maintaining the availability of a technological equipment to zero defects / zero stops scenario - which would signify that no interrupts will appear in the production process due to equipment malfunction;

Maintenance must contribute to the increase of the efficiency for the base activity of the industrial firm thus it has to be organized in such a way as to become a profit center for the company.

The evaluation of the non-maintenace cost represents an important indicator for analyzing activity efficiency and illustrate profit losses at the company level by not implementing necessary maintenance activities that would lead to the zero defects scenario. 


\section{Bibliography:}

1. Boucly, F., Maintenance les coutes de non-efficacite, AFNOR, Paris, France, 1987

2. Cucu, I., Managementul mentenanței industriale, Ed Universității din Petroşani, 2000

3. Deac V., Managementul mentenanței industriale, Editura Eficient, Bucureşti, 2000

4. Dura C., Isac C., Economia întreprinderii, Editura Universitas, Petroşani, 2006

5. Nakajima, S - Introduction to Total Productive Maitntenance, Productivity Press, Cambridge U.S.A., 1988

6. Revelin, C - Evaluation de Coutes, ENS-NP, Paris, France,1985. 